\title{
Presparking Effect in Spark Source Mass Spectrometry
}

\author{
A. Harfoush \\ Atomic Energy Commission of Syria, Damascus, Syria
}

S. Sh. Soulayman

High Institute for Applied Sciences and Technology, Damascus, Syria

Z. Naturforsch. 47 a, $748-752$ (1992); received September 12, 1989

\begin{abstract}
The Relative Sensitivity Factor (RSF) in Spark Source Mass Spectrometry analysis was found to be dependent on the number and duration of previous sparking periods. This dependency becomes very strong when dealing with volatile elements. By statistical analysis of experimental RSF values it was found that there is a linear correlation between $\ln (\mathrm{RSF})$ of some trace elements and their boiling temperature. This correlation fails when dealing with volatile elements and carbon. It was found that elements with a large diffusion coefficient have a large RSF.
\end{abstract}

Key words: Relative Sensitivity Factor; Spark Source Mass Spectrometry; Presparking effect; Boiling temperature; Diffusion.

Spark Source Mass Spectrometry (SSMS) is a technique for making trace analyses of almost all elements even at ppb level. But numerous analyses made by SSMS of different materials show that the Relative Sensitivity Factor (RSF) (defined as the measured ratio of the concentrations of an element and a standard element devided by the true ratio in the matrix material) of many elements varies considerably from one matrix to another. It was also found that the RSF is influenced by the shape of the sample electrodes [1], the spark gap width [2], the spark voltage [3], the repetition frequency, the accelerating voltage [3], etc.

Several formulae have been suggested correlating the RSF with physical properties of the element in question, such as melting point [4], boiling point [4-6], heat of sublimation [4], ionization potential [6], bond (dissociation) energy [6], etc. These formulae are only useful for making analyses of matrices similar to those from which they are deduced. Also they often fail in predicting the RSF not only for volatile elements but also for certain other elements such as boron [6] and carbon [7].

The RSF strongly depends on the temperature of the sample electrode $[1,8]$, specially for volatile elements. In the present paper the presparking effect on the RSF is studied.

Reprint requests to Dr. S. Sh. Soulayman, High Institute for Applied Sciences and Technology, P.O. Box 7028, Damascus, Syrien.

\section{Experimental}

This work was carried out with a double focusing mass spectrometer. AEI MS $702 \mathrm{R}$, with MattauchHerzog geometry. Details of the instrument are given in [9]. All the spectra were recorded on ion-sensitive Ilford Q2 plates which have the following characteristics: coating weight $0.5 \mathrm{mg} \mathrm{cm}^{-2}$, silver weight $0.19 \mathrm{mg} \mathrm{cm}^{-2}$, coating thickness $2.1 \mu \mathrm{m}$, grain dimension $0.8 \mu \mathrm{m}$, grain shape hexagonal, detection sensitivity $1.1 \times 10^{-7} \mathrm{~cm}^{2}$ ion $^{-1}$. The measurements were done with a microphotometer type G2 (Zeiss, Jena, DDR) at the Central Research Institute for Physics in Budapest [10]. The optical system was modified to be a double beam system.

The material studied were aluminium $5005 \mathrm{~A}$ from Alcan International Limited (Canada), which contains 28 elements, 22 of them being certified, and iron alloy SRM 1219 from National Bureau of Standards, containing 19 elements, 11 of them being certified. The concentrations of the trace elements observed in these two materials are given in Table 1.

To prepare a sample, a pair of cylindrical electrodes (10 mm long, $0.5 \mathrm{~mm}$ thick) was cut from the bulk. Attention was paid to fabricate the electrodes at low temperature in order to conserve the sample homogeneity. Then the electrodes were cleaned with acetone and washed with double distilled water. After attainment of vacuum $\left(4 \times 10^{-8}\right.$ torr $)$ the electrodes were intermittently sparked for less than 3 seconds, amount- 
Table 1. True concentrations of trace elements in $5005 \mathrm{~A}$ and SRM 1219. + denotes the noncertified elements.

\begin{tabular}{|c|c|c|}
\hline Element & $\begin{array}{l}5005 \mathrm{~A} \\
\text { Concentration } \\
\text { (weight \%) }\end{array}$ & $\begin{array}{l}\text { SRM } 1219 \\
\text { Concentration } \\
\text { (weight \%) }\end{array}$ \\
\hline $\mathrm{Cd}$ & 0.019 & \\
\hline $\mathrm{Na}$ & 0.0008 & \\
\hline $\mathrm{Zn}$ & 0.039 & \\
\hline $\mathrm{Mg}$ & 0.88 & \\
\hline $\mathrm{Li}$ & 0.0003 & \\
\hline $\mathrm{Sr}$ & + & \\
\hline $\mathrm{Ca}$ & 0.0023 & \\
\hline $\mathrm{Bi}$ & 0.019 & \\
\hline $\mathrm{Pb}$ & 0.020 & + \\
\hline $\mathrm{Sb}$ & + & \\
\hline $\mathrm{Mn}$ & 0.055 & 0.42 \\
\hline $\mathrm{Sn}$ & 0.024 & + \\
\hline $\mathrm{Si}$ & 0.16 & 0.545 \\
\hline $\mathrm{Ga}$ & 0.028 & \\
\hline $\mathrm{Al}$ & Matrix & + \\
\hline B & + & + \\
\hline $\mathrm{Cu}$ & 0.07 & 0.162 \\
\hline $\mathrm{Cr}$ & 0.030 & 15.64 \\
\hline $\mathrm{Ni}$ & 0.033 & 2.12 \\
\hline $\mathrm{Fe}$ & 0.54 & Matrix \\
\hline Co & 0.020 & + \\
\hline $\mathrm{Be}$ & 0.0030 & \\
\hline $\mathrm{Ce}$ & + & \\
\hline $\mathrm{Ti}$ & 0.035 & + \\
\hline V & 0.031 & 0.056 \\
\hline $\mathrm{Zr}$ & 0.018 & \\
\hline Mo & & 0.164 \\
\hline $\mathrm{Nb}$ & + & \\
\hline $\mathrm{C}$ & & 0.149 \\
\hline W & & + \\
\hline$P$ & 0.0028 & 0.026 \\
\hline $\mathrm{Ba}$ & + & \\
\hline S & & 0.001 \\
\hline $\mathrm{N}$ & & 0.078 \\
\hline
\end{tabular}

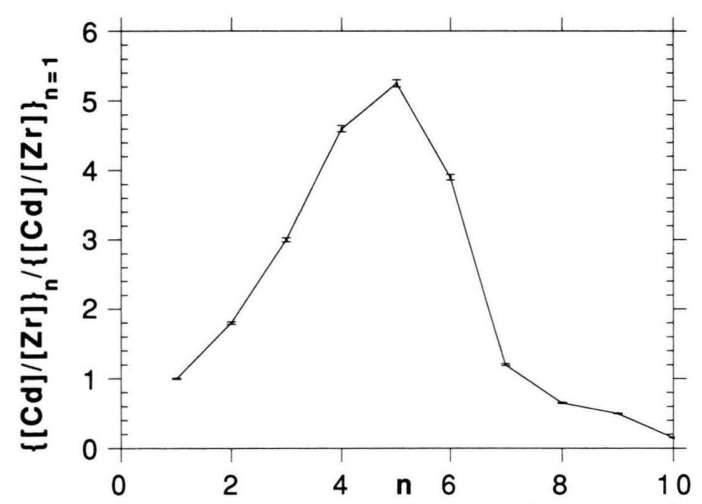

Fig. 1. Measured $\{[\mathrm{Cd}] /[\mathrm{Zr}]\}_{n} /\{[\mathrm{Cd}] /[\mathrm{Zr}]\}_{n=1}$ vs. $n$ for aluminium $(5005 \mathrm{~A})$. The number of nonexposed presparkings is $n-1$. ing to a total time of about 30 seconds, in order to clean the electrode surface. All results given in this work were obtained after this cleaning procedure. For cooling, a liquid nitrogen finger was connected to the electrodes by braids of copper.

During sparking, the electrodes were facing each other. The conditions throughout the work were: sparking voltage $30 \mathrm{kV}$, pulse width $100 \mu \mathrm{s}$, repetition frequency $300 \mathrm{~Hz}$, accelerating voltage $24 \mathrm{kV}$. An autospark was also used to make the spark intensity as constant as possible.

We only took into consideration elements which have at least one isotope free of interferences, even for the noncertified ones, and we only used singly charged monoatomic ions for the determination of RSFs.

The RSF

$$
\operatorname{RSF}\left(\frac{X}{Y}\right)_{Z}=\left\{\frac{\left(\frac{[X]}{[Y]}\right)_{\text {measured }}}{\left(\frac{[X]}{[Y]}\right)_{\text {true }}}\right\}_{Z}
$$

represents the measured ratio of the concentrations of elements $X$ and $Y$ divided by the true ratio in the matrix material $Z$. In (1), $Y$ is taken as a standard.

We used chromium (boiling temperature $2480^{\circ} \mathrm{C}$ ) as an internal standard for the two studied matrices because its isotope ${ }^{52} \mathrm{Cr}$ did not interfere with other isotopes.

\section{Results}

Van Hoye et al. [8] found that the RSF of volatile elements has a tendency to decrease on cooling the electrodes. On the other hand, Verlinden et al. [11] found that after sparking the concentration of volatile elements increases with increasing depth of the analysed layer, the distribution of the elements having been homogeneous before sparking.

Therefore we decided to investigate the presparking effect, and we made a series of measurements with cooled new electrodes of aluminium (5005 A) using 15 min intervals between successive sparkings in order to let the electrode temperature return to its initial value after each presparking. Each sparking had a duration of $12 \mathrm{sec}$. So, each exposure $n$ of the plate can be characterized by the number $n-1$ of nonexposed presparkings.

For the aluminium (5005 A) matrix our results $\{[\mathrm{Cd}] /[\mathrm{Zr}]\}_{n} /\{[\mathrm{Cd}] /[\mathrm{Zr}]\}_{n=1}$ are presented in Fig. 1, 
where

$$
\left\{\frac{[\mathrm{Cd}]}{[\mathrm{Zr}]}\right\}_{n}=\left(\frac{[\mathrm{Cd}]}{[\mathrm{Zr}]}\right)_{\text {true }}\left\{\frac{\operatorname{RSF}\left(\frac{\mathrm{Cd}}{\mathrm{Cr}}\right)}{\operatorname{RSF}\left(\frac{\mathrm{Zr}}{\mathrm{Cr}}\right)}\right\}_{n} .
$$

$\mathrm{Cd}$ and $\mathrm{Zr}$ with their boiling temperatures 765 and $3580{ }^{\circ} \mathrm{C}$, respectively, are taken as volatile and nonvolatile elements. A similar curve is obtained if, instead of $\mathrm{Cd}$, a nonvolatile element (say $\mathrm{Cr}$ ) is taken, but in this case the maximum value is much lower. It is concluded from Fig. 1 that the upper layers of the electrode become so depleted of $\mathrm{Cd}$ that the measured $[\mathrm{Cd}] /[\mathrm{Zr}]$ goes down after the first sparkings.

We have also made a series of measurements with 10 cooled new electrode pairs of aluminium (5005 A). Electrode pair $i(i=1,2, \ldots, 10)$ was sparked (and the plate exposed) for the accumulated time $t_{i}=\sum_{k=1}^{i} \tau_{k}$. The intervals between successive sparking times $\tau_{k}$ were again $15 \mathrm{~min}$. Since $\tau_{k}$ is proportional to $q_{k}$, the charge to which the photoplate has been exposed during the time $\tau_{k}$, we can say that, during the accumulated time $t_{i}$, the photoplate was exposed to a total charge $Q_{i}=\sum_{k=1}^{i} q_{k}$. Here it was found, see Fig. 2, that the RSF for $[\mathrm{Cd}] /[\mathrm{Zr}]$ starts to be approximately constant when $Q_{i}$ reaches $6 \mathrm{nC}$. We have measured asymptotic RSF values with $\mathrm{Cr}$ as standard for most of the trace elements in 5005 A and SRM 1219 matrices. The results are presented in Table 2.

\section{Discussion}

It has been suggested by different authors (see for example $[4,5,12]$ that the asymptotic RSF (see Table 2) for nonvolatile elements follows the relation

$$
\mathrm{RSF}=A \exp \left(-B T_{\mathrm{b}}\right),
$$

where $A$ and $B$ are constants and $T_{\mathrm{b}}$ (expressed in ${ }^{\circ} \mathrm{C}$ ) is the boiling temperature of the element in consideration. It has been suggested [4] that the influence of different matrices shows up in $A$ rather than in $B$. In [5] the proposed formula is said to be valid only when the boiling temperature of the trace element exceeds that of the matrix, while Kunstar et al. [12] used the heat of sublimation of the studied element as well as its boiling temperature. Ito et al. [4] suggested a correlation between the RSF and the melting point, boiling point or heat of sublimation.

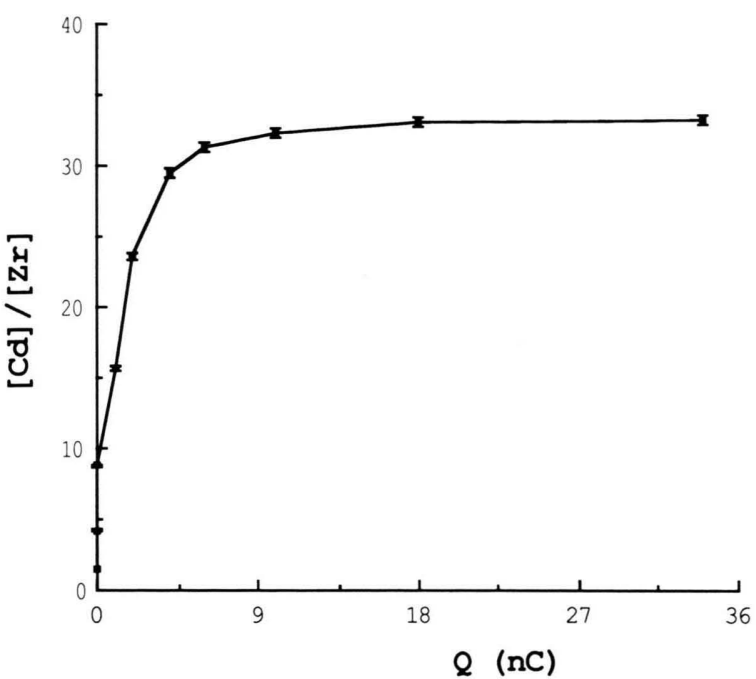

Fig. 2. Measured ${ }^{111} \mathrm{Cd}$ to ${ }^{90} \mathrm{Zr}$ vs. accumulated charge $Q_{i}$ (in $\mathrm{nC})$, to which the photoplate was exposed, for $5005 \mathrm{~A}$.

Table 2. Measured asymptotic RSFs of trace elements in the matrices 5005A and SRM 1219. ++ denotes elements for which the RSF was not determined.

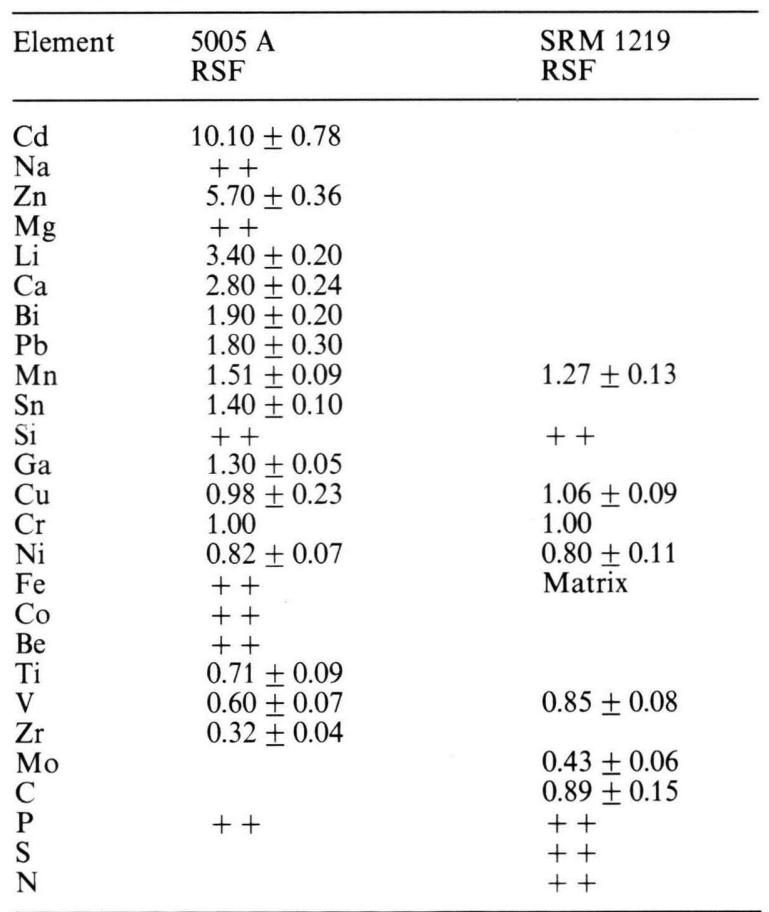

In this work, $A$ and $B$ (the linear regression coefficients of (3)) were determined for the trace elements in the 5005A and SRM 1219 matrices. The obtained values of $A$ and $B$ for these two matrices are 5.76, $6.58 \times 10^{-4}{ }^{\circ} \mathrm{C}^{-1}$ and $2.90,4.06 \times 10^{-4}{ }^{\circ} \mathrm{C}^{-1}$, respectively. It was found here that the correlation coeffi- 


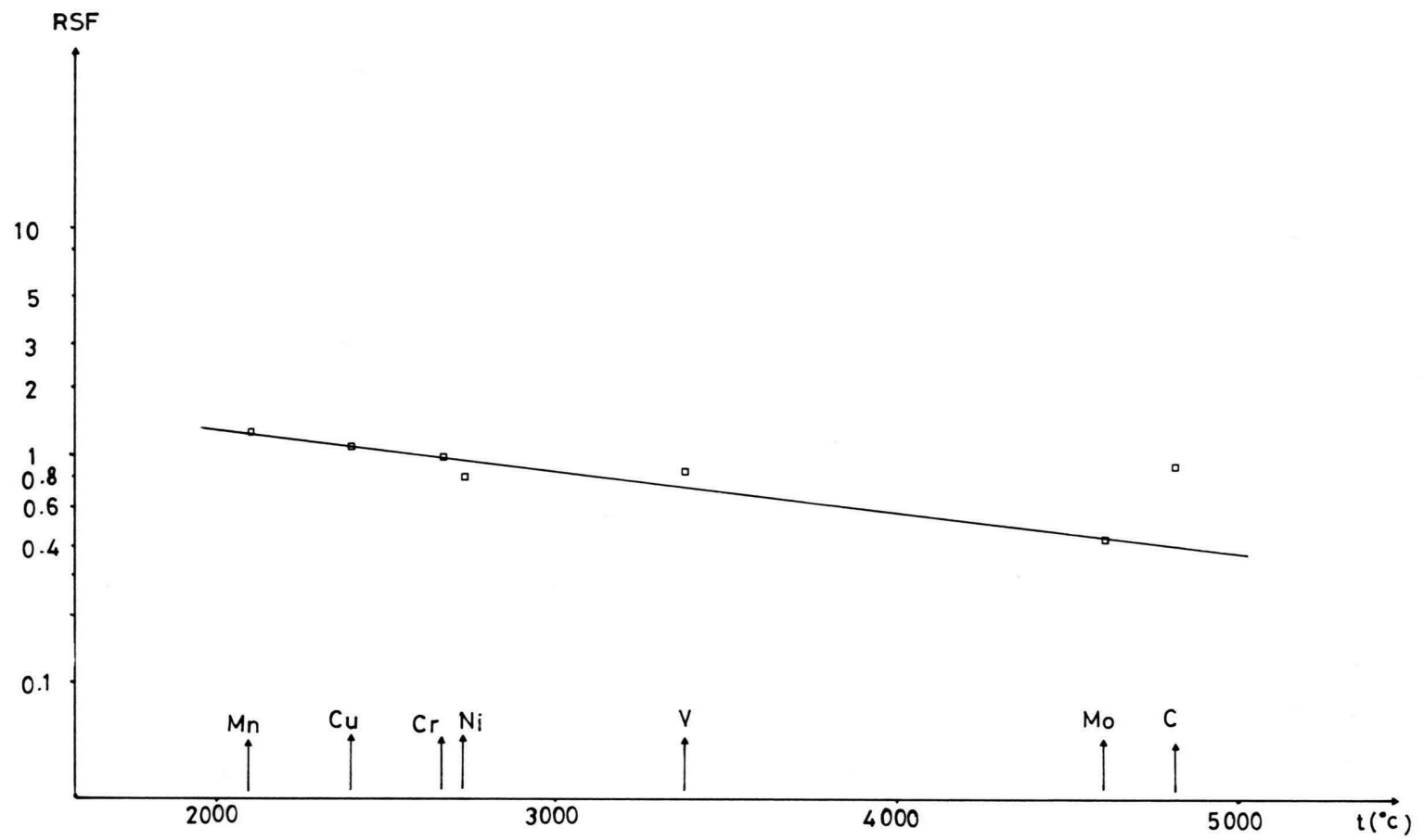

Fig. 3. Experimental RSF values for the iron alloy SRM 1219 vs. boiling temperature of the indicated nonvolatile trace elements. $\square$ measured values, $\longrightarrow$ theoretical values (3).

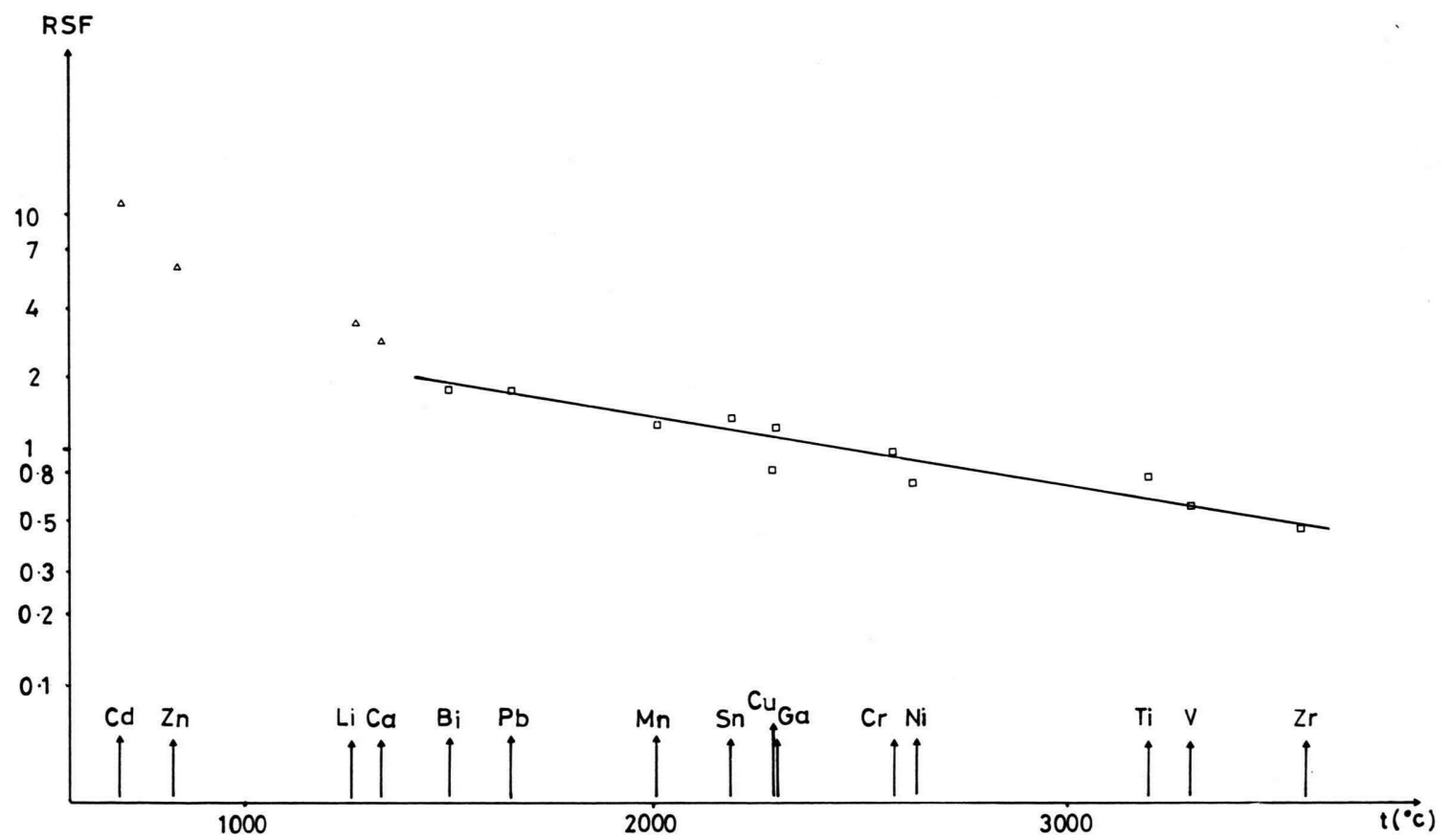

Fig. 4. Experimental RSF values for the aluminium $5005 \mathrm{~A}$ vs. boiling temperature of the indicated trace elements. $\Delta$ and $\square$ measured values for volatile and nonvolatile elements, respectively, $\frac{-}{-}$ theoretical values (3). 


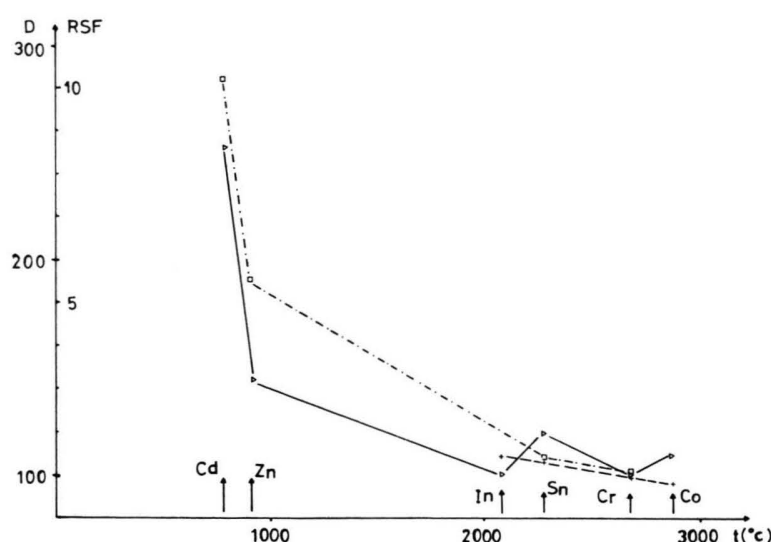

Fig. 5. Experimental RSFs (ם), calculated RSFs (+) (see (3)), and diffusion coefficients $D$ expressed in $10^{-10} \mathrm{~cm}^{2} / \mathrm{s}(\triangleright)$ at $600{ }^{\circ} \mathrm{C}$ in aluminium matrix versus boiling temperature of the elements indicated.

cients are different for our two matrices when we consider elements found in both matrices. Our results confirm the remarks of $[13,14]$ and Ito et al. [4] on the matrix effect. Our RSF values in SRM 1219 (see Fig. 3 and Table 2) confirm the carbon values of Ahearn [7]. In addition, the RSF values for volatile elements in 5005 A (see Fig. 4 and Table 2) were found to be large too, in agreement with other authors $[6,7]$. On the other hand, the exclusion of some RSF values (of volatile elements and carbon), from the fitting of (3) to the experimental data, indicates the restriction of empirical formulae correlating the RSF with physical properties and the difficulty of going on with this conception.

Many attempts have been made to explain the variation of RSF values. The diffusion process has been discussed in [5]. Therefore, the RSF of $\mathrm{Zn}$ and $\mathrm{Cd}$ as volatile elements and $\mathrm{Co}, \mathrm{Cr}, \mathrm{Sn}$ and $\mathrm{In}$ as nonvolatile

[1] J. Franzen, Z. Naturforsch. 18a, 410 (1963).

[2] C. W. Magee and W. W. Harison, Anal. Chem. 45, 852 (1973).

[3] N. Yamaguchi, R. Suzuki, and O. Kammori, Bunseki Kagaku 18, 3 (1969).

[4] M. Ito, Sh. Sato, and K. Yanagihara, Anal. Chim. Acta 120, 217 (1980).

[5] N. W. H. Addink, Z. Anal. Chem. 206, 81 (1964).

[6] B. P. Datta and H. C. Jain, Int. J. Mass Spectr. Ion Proc. 68, 219 (1986).

[7] A. J. Ahearn (ed.), Trace Analysis by Mass Spectrometry, Academic Press, New York 1972.

[8] E. Van Hoye, F. Adams, and R. Gijbels, Int. J. Mass Spectr. Ion Phys. 30, 75 (1979); Talanta 25, 73 (1978).

[9] I. Opauszky and I. Nyary, Report KFKI-1981-09. This report can be found at Central Research Institute for Physics, H-1525 Budapest 114, P.O. Box 49, Hungary (ISBN 96371786 8; HU ISSN 68 5330). ones were compared here with their diffusion coefficients $\mathrm{D}$ in aluminium [15-17] at $600{ }^{\circ} \mathrm{C}$. The melting temperature of aluminium is $661{ }^{\circ} \mathrm{C}$ [18]. Figure 5 shows that the nonvolatile elements $(\mathrm{Co}, \mathrm{Cr}, \mathrm{Sn}$ and In) have small diffusion coefficients while the volatile elements ( $\mathrm{Cd}$ and $\mathrm{Zn}$ ) have larger ones. The same was also found for carbon.

The obtained results give some arguments to explain high RSF values: Sparking depletes the concentration of the trace elements at the surface of the electrode. At first, this depletion is the lower, the higher the diffusion coefficient of the considered element. Later on, however, the concentration gradient of this element becomes lower than that of an element with a lower diffusion coefficient. Therefore, $[\mathrm{Cd}] /[\mathrm{Zr}]$ vs. $n$ shows a maximum in Figure 1.

\section{Conclusion}

Our results clearly demonstrated the influence of presparking on SSMS analysis. Some relation seems to exist between the RSF of the trace element and its diffusion ability.

\section{Acknowledgements}

The authors express their gratitude to the members of the Spark Source Mass Spectrometry Laboratory in the Research Institute for Physics in Budapest for their valuable discussion and some technical assistance of this work. We have enjoyed discussions with Ch. Simon, G. Hauchecorne (Groupe de Physique des Solides, Universite Paris VII) and J. F. Hennequin (CNRS, Laboratoire PMTM, Universite Paris Nord). Many thanks to A. Mouhamad for his assistance on the technical side.

[10] J. Frecska and M. Kunstar, 4th Int. Conf. on Mass Spectral Analysis (SSMS and SIMS), Donovaly, Czechoslovakia, Oct. 31 -Nov. 3 (1988).

[11] J. Verlinden, K. Swenters, and R. Gijbels, Spectrochim. Acta, Part B, GB, 39 B, (12) 1573 (1984).

[12] M. Kunstar, I. Nyary, I. Pummer, and I. Opauszky, Acta Chemica 124, 931 (1987).

[13] L. Rademarcher and H. E. Beske, Spectrochim. Acta Part B 34, 105 (1979).

[14] L. Luck, W. Szacki, and E. Pluhar, Fresenius Z. Anal. Chem. 309, 281 (1981).

[15] N. L. Peterson and S. J. Rothman, Phys. Rev. B 1, 3264 (1970).

[16] W. B. Alecsander and L. M. Slifkin, Phys. Rev. B 1, 3274 (1970).

[17] M. S. Anand and R. P. Agarwaal, Phys. Stat. Solidi A 1, K 41 (1970).

[18] Yu. M. Mishin and I. M. Razumovskii, Phys. Stat. Solidi A 117, 91 (1989). 